\title{
Soil contamination by phthalate esters in Chinese intensive vegetable production systems with different modes of use of plastic film
}

\author{
Jun Wang ${ }^{a}$, Yongming Luo ${ }^{b}$, Ying Teng ${ }^{a}, *$, Wenting Ma ${ }^{a}$, Peter Christie ${ }^{c}$, Zhengao Li $^{a}$ \\ ${ }^{a}$ Key Laboratory of Soil Environment and Pollution Remediation, Institute of Soil Science, Chinese Academy of Sciences, Nanjing 210008, China \\ ${ }^{\mathrm{b}}$ Yantai Institute of Coastal Zone Research, Chinese Academy of Sciences, Yantai 264003, China \\ ${ }^{\mathrm{c}}$ Agri-Environment Branch, Agri-Food and Biosciences Institute, Newforge Lane, Belfast BT9 5PX, United Kingdom
}

\section{A R T I C L E I N F O}

Article history:

Received 9 December 2012

Received in revised form 20 May 2013

Accepted 21 May 2013

\section{Keywords:}

Phthalate esters

Plastic film

Plasticizers

Soil contamination

Vegetable production

\begin{abstract}
A B S T R A C T
The concentrations of six priority phthalic acid esters (PAEs) in intensively managed suburban vegetable soils in Nanjing, east China, were analyzed using gas chromatography-mass spectrometry (GC-MS). The total PAE concentrations in the soils ranged widely from 0.15 to $9.68 \mathrm{mg} \mathrm{kg}^{-1}$ with a median value of $1.70 \mathrm{mg} \mathrm{kg}^{-1}$, and di-n-butyl phthalate (DnBP), bis-(2-ethylhexyl) phthalate (DEHP) and di-n-octyl phthalate (DnOP) were the most abundant phthalate esters. Soil PAE concentrations depended on the mode of use of plastic film in which PAEs were incorporated as plasticizing agents and both the plastic film and poultry manure appeared to be important sources of soil PAEs. Vegetables in rotation with flooded rice led to lower concentrations of PAEs in soil. The results indicate that agricultural plastic film can be an important source of soil PAE contamination and further research is required to fully elucidate the mechanisms of PAE contamination of intensive agricultural soils with different use modes of use of plastic film.
\end{abstract}

Crown Copyright @ 2013 Published by Elsevier Ltd. All rights reserved.

\section{Introduction}

Phthalic acid esters (PAEs) are commonly used to increase the flexibility, pliability and elasticity of plastic products (Chou and Robert, 2006). They are widely used in general plastic products, cosmetics, personal care products, food packaging and medical products (Van Wezel et al., 2000; Hens and Caballos, 2003; Cai et al., 2008; Xia et al., 2011). The global consumption of PAEs is about 6.0 million tons per annum (Xie et al., 2007). As a result of their large-scale production and widespread application, PAEs can enter into the environment during the manufacture, use and disposal of plastics (Kong et al., 2012). Numerous studies have revealed the presence of PAEs in various environmental media such as water (Xie et al., 2007), air (Wang et al., 2012), sediments (Cai et al., 2008; Srivastava et al., 2010) and soils (Ma et al., 2003; Zeng et al., 2008; Kong et al., 2012), and they have also been detected in epoxidized soybean oil, soft spreadable cheese, sauces, and peanut butter (Pedersen et al., 2008) and in many types of vegetable (Fu and Du, 2011). DnBP, DEHP, butyl benzyl phthalate (BBP), diethyl phthalate (DEP) and diheptyl phthalate have endocrine disruptive effects in vivo (Hens and Caballos, 2003).

\footnotetext{
* Corresponding author.

E-mail address: yteng@issas.ac.cn (Y. Teng).
}

Furthermore, their metabolites are suspected endocrine disrupting chemicals exhibiting carcinogenic action (McKee et al., 2004). Human Leydig cell development and function may be vulnerable and incomplete virilization in infant boys due to perinatal exposure to some phthalates (Main et al., 2006). Moreover, inhalation of substantial amounts of phthalates or their metabolites by women during pregnancy can result in abortion (Adibi et al., 2003). The United States Environmental Protection Agency (USEPA) has classified dimethyl phthalate (DMP), DEP, DBP, BBP, DEHP and DnOP as priority environmental pollutants (USEPA, 2013). PAEs have become one of the most widespread classes of organic contaminants, which have attracted much attention on a global scale (Kong et al., 2012).

Urbanization and industrial modifications of the environment in China interact strongly with agricultural production (Khai et al., 2007; Zeng et al., 2008) and land use in suburban areas has changed from paddy fields to more economically lucrative intensive vegetable systems. Many agricultural soils have been severely degraded by agricultural activities and urban development (Zeng et al., 2009; Gu et al., 2011). Numerous studies have indicated that agricultural soils and vegetables have been contaminated by toxic pollutants (Gao et al., 2005). Some investigators have found that toxic pollutants such as heavy metals (Hu and Ding, 2009), polycyclic aromatic hydrocarbons (PAHs) (Yin et al., 2008), persistent organic pollutants (POPs) (Gao et al., 2005), organochlorine 
pesticides (Tao et al., 2005) and PAEs are present in suburban agricultural soils (Chen et al., 2011; Xia et al., 2011; Kong et al., 2012). PAEs are among the most abundant semi-volatile organic chemicals found in Chinese soils (Cai et al., 2008). Soils are environmental matrices that can transfer pollutants to plants and the human food chain. DnBP has negative impacts on the vitamin $C$ and capsaicin contents of capsicum fruit (Yin et al., 2003). The uptake of DEHP by nine types of greenhouse vegetable varied from 10.14 to $36.16 \mathrm{mg} \mathrm{kg}^{-1}$ (Fu and Du, 2011). The use of large amounts of agricultural plastic film and fertilizers containing PAEs in intensive vegetable cultivation might increase the health risk of PAEs through the food chain (Mo et al., 2008; Pedersen et al., 2008; Kong et al., 2012). High levels of PAEs in agricultural soils have already been reported in the Pearl River Delta (Cai et al., 2005; Zeng et al., 2008; Zhang et al., 2009) and northeast China (Xu et al., 2008). The respective mean concentrations of DnBP and DEHP found in greenhouse soils were 1.63 and $1.96 \mathrm{mg} \mathrm{kg}^{-1}$ in Jinan, Shandong province (Meng et al., 1996), 0.60 and $0.63 \mathrm{mg} \mathrm{kg}^{-1}$ in Beijing (Ma et al., 2003), 15.5 and $4.61 \mathrm{mg} \mathrm{kg}^{-1}$ in Handan, Hebei province (Xu et al., 2008) and 0.21 and $1.48 \mathrm{mg} \mathrm{kg}^{-1}$ in Hangzhou, Zhejiang province (Chen et al., 2011). The concentrations of DnBP and DEHP in plastic film greenhouse and polytunnel soils may been influenced by differences in the use of irrigation, fertilizers and plastic film as well as meteorological conditions and external pollutant sources (Mo et al., 2008; Cai et al., 2008; Kong et al., 2012). Soil PAEs can also lead to atmospheric or water pollution by evaporation, leaching, deposition and drainage (Xu et al., 2008; Zeng et al., 2009; Wang et al., 2012).

The consumption of PAEs in China in 2011 was about 2.2 million tons, most of which was used in the production of plastic film (CPPIU, 2011). Plastic film generally comprises the walls of polytunnels or for mulching at the soil surface in intensive vegetable cultivation. The total mulching area in China was 15.6 million hectares by 2010 (China Agriculture Yearbook, 2011). Different plastic films, fertilizers and pesticides containing PAEs are applied to intensive vegetable production soils and different use modes of plastic film are practiced (Fu and Du, 2011). However, there is little information on the distribution of PAEs in soils used for vegetable production. The primary objectives of the present study were therefore to investigate PAE concentrations in suburban vegetable soils with different use modes of plastic film use, to identify the sources of the PAEs found, and to determine their environmental risk. The study was designed to provide preliminary data to help inform land managers for the control of PAEs in agricultural soils used to grow vegetables for human consumption.

\section{Materials and methods}

\subsection{Soil sampling}

One hundred and twenty-seven soil samples (0-15 cm depth) from vegetable production with different use modes of plastic film and thirty-two samples of plastic film and poultry manure were collected from four vegetable production areas in Jiangning and Lishui districts of Nanjing, east China in January 2012. The sampling locations were recorded by GPS and are shown in Fig. 1. Forty-one soil samples were collected from Guli (GL) where the vegetables had been cultivated for 8-12 years with double polytunnels and a single layer of mulch film. The outer polytunnel film remained in position throughout the year and the small inner polytunnel was used during winter to spring (Fig. 2A). Thirty-three samples were collected from Hushu (HS) where the typical production system comprised vegetables and flooded rice in rotation for about 4 years (Fig. 2B). Twenty-nine samples were collected from Suoshi (SS) where vegetables had been cultivated for over 10 years with a single layer of polytunnel and mulch film (Fig. 2C). Twenty-four samples were from Pulangke (PK) where vegetables had been grown for over 10 years with the sequence of single layer polytunnels during the whole year for two years with mulching film and then one year with mulching film but without polytunnels (Fig. 2D). The first two soil samples from each location (representing each use mode of plastic film) were collected from where the vegetables had been grown without polytunnel and mulching film and served as controls (CK). All of the soil samples collected from each site were obtained from different field sites in the locality. The physico-chemical properties of the top $15 \mathrm{~cm}$ of the soil at the four sites were determined and the mean values were: $\mathrm{pH}$ $\left(\mathrm{H}_{2} \mathrm{O}\right)$, 7.4; soil organic carbon, $25.2 \mathrm{~g} \mathrm{~kg}^{-1}$; total $\mathrm{N}, 1.53 \mathrm{~g} \mathrm{~kg}^{-1}$; total $\mathrm{P}, 1.80 \mathrm{~g} \mathrm{~kg}^{-1}$; and clay, $15.2 \%(\mathrm{v} / \mathrm{v})$. Both polytunnel film and mulch film were used and were composed of polyethylene. Two colors of mulch film were used, namely black and white. The thickness of the greenhouse film at GL, SS, HS and PK was 0.12, 0.14, 0.60 and $0.15 \mathrm{~mm}$, respectively. The mulch film width $\times$ thickness at GL, SS, HS and PK was $2000 \times 0.003,2000 \times 0.004,2000 \times 0.006$ and $2000 \times 0.002 \mathrm{~mm}$.

Soil samples were collected from the top $15 \mathrm{~cm}$ of the profile using a pre-cleaned stainless soil auger and transferred into cloth bags. Small pieces of vegetation and litter were removed before transfer. Each soil and poultry manure sample consisted of five sub-samples collected from the area of each site (within $60 \times 10 \mathrm{~m}^{2}, 1 \mathrm{~kg}$ each) and were cooled in an ice box during transport. Precautions were taken during sampling and sample processing to avoid PAE contamination. Soil and poultry manure samples were freeze-dried, ground and homogenized by sieving through a stainless steel sieve (60-mesh) after removing stones and residual roots and then sealed in brown glass bottles. The plastic film samples were rinsed clean with deionized water, allowed to dry at ambient temperature, cut into pieces $0.5 \times 0.5 \mathrm{~mm}$, and sealed in Kraft paper bags. All the soil, fertilizer and plastic film samples were stored at $-20^{\circ} \mathrm{C}$ until analysis.

\subsection{Sample extraction}

Mixed standard solutions containing DMP, DEP, DBP, BBP, DEHP and DOP (1 mg mL $\mathrm{mb}^{-1}$ ) and isotope surrogate standard di-n-butyl phthalate-d4 (DnBP-D4, $100 \mu \mathrm{g} \mathrm{mL}^{-1}$ ) were supplied by Dr. Ehrenstorfer $\mathrm{GmbH}$, Augsburg, Germany. The stock solutions of six mixed phthalates were prepared in n-hexane at a concentration of $1 \mathrm{mg} \mathrm{L}^{-1}$. Acetone and $\mathrm{n}$-hexane were obtained from Nanjing chemical reagent companies and were re-distilled in glass before use to avoid PAE contamination. HPLC grade hexane was purchased from Tedia Company Inc., Fairfield, $\mathrm{OH}$. All glassware was washed in detergent solution in a laboratory ultrasonic washer (KQ-600DB, Kun Shan Ultrasonic Instruments Co., Ltd., Jiangsu province, east China) and air dried, then immersed in sulfuric acid (guaranteed reagent) and
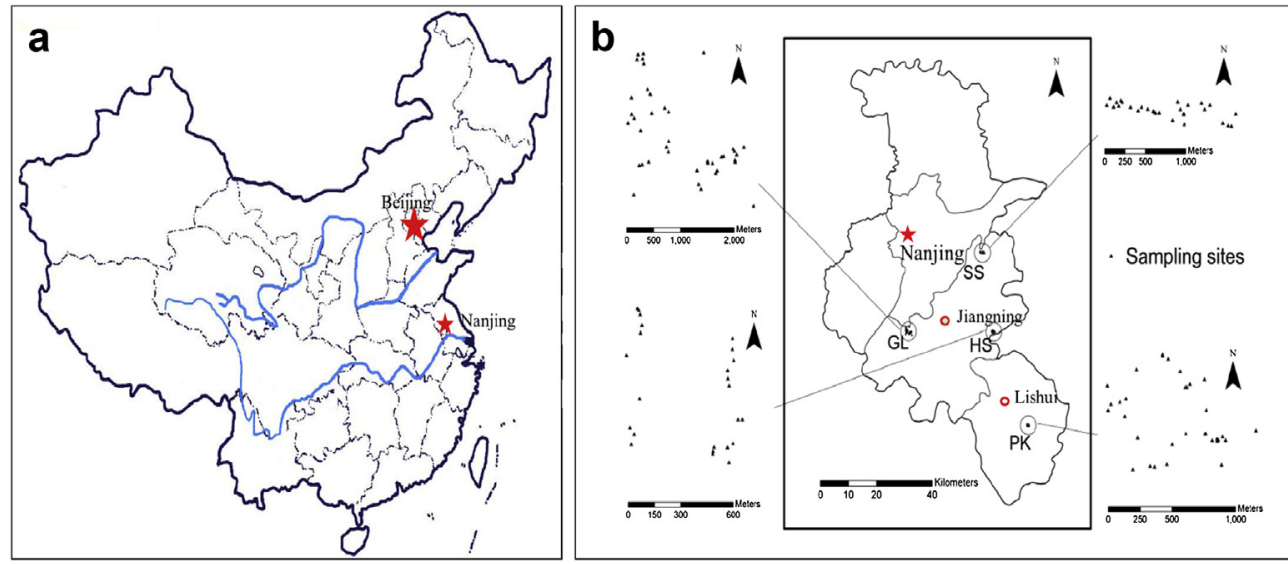

Fig. 1. Schematic map showing the geographical location of (a) Nanjing city and (b) the vegetable soil sampling sites in the Nanjing suburbs within the Nanjing region. 


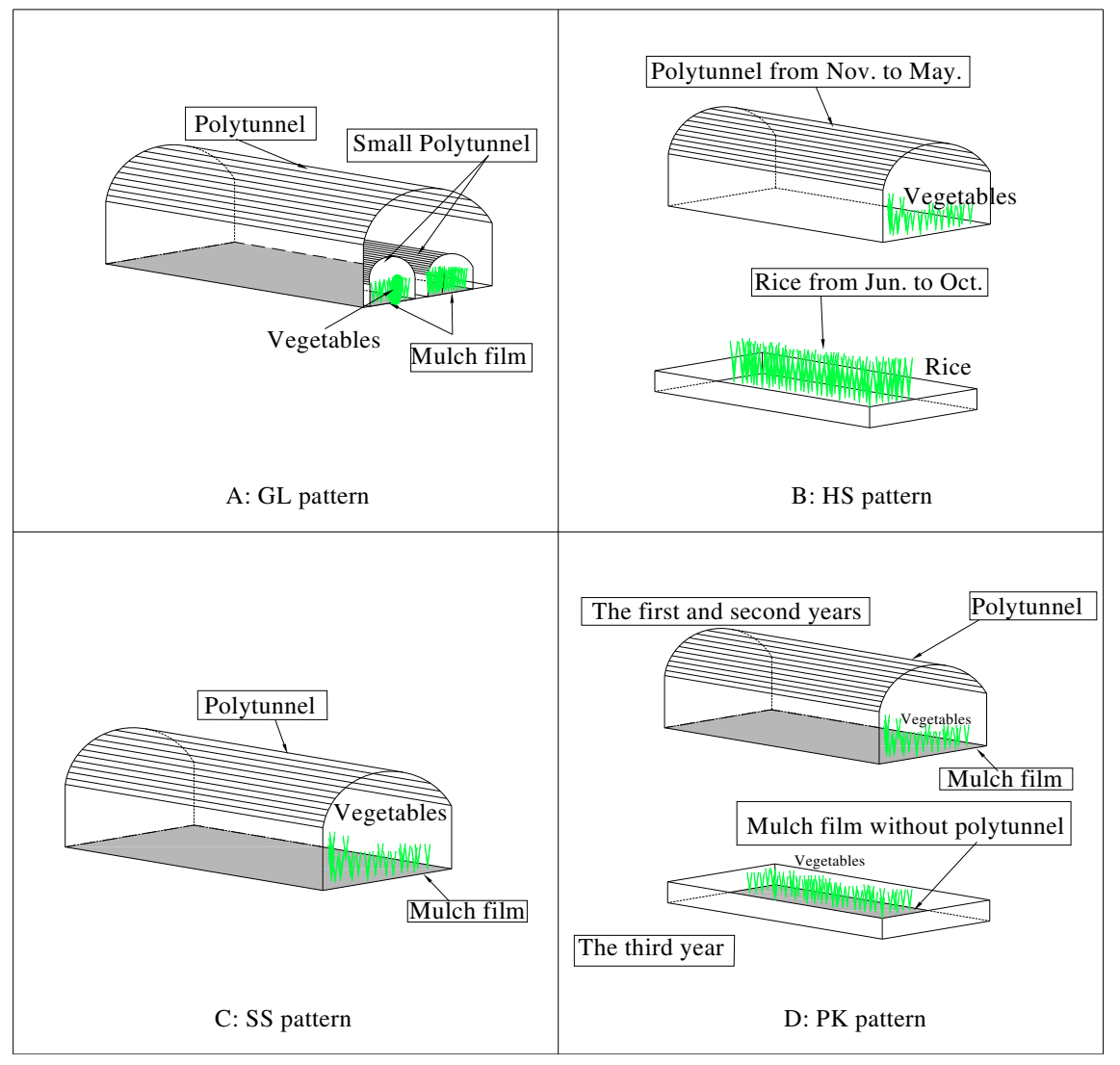

Fig. 2. Diagram showing the four modes of use of plastic film.

washed with tap water and ultrapure water before oven-drying. The glassware was rinsed again with acetone:hexane $(1: 1 \mathrm{v} / \mathrm{v})$ before use. No plastic vessels were used in the experimental procedures.

\subsection{Analytical procedures}

Soil $(5.0 \mathrm{~g})$, fertilizer or poultry manure $(2.0 \mathrm{~g})$, or plastic film $(1.0 \mathrm{~g})$ was weighed into a glass centrifuge bottle and mixed with $20 \mathrm{~mL}$ acetone:hexane ( $1: 1 \mathrm{v}$ $v)$, left overnight and extracted for $30 \mathrm{~min}$. The extract was then filtered into a round bottom flask and the procedure was repeated a further two times. All of the filtrate was concentrated to $1-2 \mathrm{~mL}$ with a rotary evaporator and $5 \mathrm{~mL}$ HPLC hexane was added to exchange the acetone, then concentrated to less than $1 \mathrm{~mL}$ and isotope surrogate standard was added to the extract, adjusted to a constant volume of $1 \mathrm{~mL}$ and transferred through a $0.25 \mu \mathrm{m}$ membrane filter to a brown sample bottle for sample injection prior to instrumental analysis.

The extracted compounds were determined with an Agilent 7890GC-5975MSD gas chromatography-mass spectrometry system (GC-MS) (Agilent Technologies, Avondale, PA) operating in electron impact and selective ion monitoring mode and with a DB-5 $(30 \mathrm{~m} \times 0.25 \mathrm{~mm} \times 0.25 \mu \mathrm{m})$ fused-silica capillary column for chromatographic separation. High purity helium (99.9999\%) was used as the carrier gas and was maintained at a constant flow rate of $1.2 \mathrm{~mL} \mathrm{~min}^{-1}$. The temperature program column oven was set to $50{ }^{\circ} \mathrm{C}$ for $1 \mathrm{~min}$ and raised to $200{ }^{\circ} \mathrm{C}$ at $15^{\circ} \mathrm{C} \mathrm{min}{ }^{-1}$, maintained for $1 \mathrm{~min}$, then up to $280{ }^{\circ} \mathrm{C}$ at $8{ }^{\circ} \mathrm{C} \mathrm{min}{ }^{-1}$ and held for $3 \mathrm{~min}$. Each extract $(1 \mu \mathrm{L})$ was injected into the GC-MS system in non-pulse and splitless mode with an injector temperature of $250^{\circ} \mathrm{C}$. The GC-MS transfer line was set at $280{ }^{\circ} \mathrm{C}$ and the post run temperature was at $285^{\circ} \mathrm{C}$ for $2 \mathrm{~min}$.

\subsection{Quality assurance and quality control}

A procedural blank, a matrix-spiked sample, a sample duplicate and a solvent blank were processed with each batch of 15 soil, poultry manure or plastic film samples. Isotope surrogate standards were added to all the samples to monitor matrix effects and the instruments were calibrated daily with calibration standards. The surrogate recoveries were $86.9 \pm 4.2 \%$ for di-n-butyl phthalate-d4. Recoveries of the 6 target PAEs ranged from 80.3 to $112.7 \%$ (relative standard deviation $<11.3 \%$ ) in the spiked blank samples, and from 76.4 to $109.5 \%$ (relative standard deviation $<9.1 \%$ ) in the spiked soil, poultry manure and plastic film matrix samples. The concentrations of the 6 target PAEs found in the procedural blanks were $0.06,0.04$,
0.08, 0.04, 0.11 and $0.08 \mu \mathrm{g} \mathrm{L}{ }^{-1}$ for DMP, DEP, DnBP, BBP, DEHP and DnOP, respectively and the values were subtracted from the sample extract results. Instrumental detection limits were calculated by a signal-to-noise ratio of 3 times the sample concentration and ranged from 0.10 to $0.31 \mu \mathrm{g} \mathrm{L}^{-1}$. The method detection limits (MDLs) were derived from the blanks and quantified as mean field blanks plus three times the standard deviation $(3 \sigma)$ of the field blanks.

\section{Results}

\subsection{PAE concentrations in suburban vegetable soils}

As shown in Fig. 3, the sum of the six measured PAEs $\left(\Sigma_{\text {PAEs }}\right)$ in soil varied considerably, ranging from 0.15 to $9.68 \mathrm{mg} \mathrm{kg}^{-1}$ with a median value of $1.70 \mathrm{mg} \mathrm{kg}-1$. Sites GL4 $\left(6.50 \mathrm{mg} \mathrm{kg}^{-1}\right)$, GL12 (7.89 $\left.\mathrm{mg} \mathrm{kg}^{-1}\right)$, GL23 (9.68 $\left.\mathrm{mg} \mathrm{kg}^{-1}\right)$, GL34 (5.12 $\left.\mathrm{mg} \mathrm{kg}^{-1}\right)$, GL35 (7.29 $\left.\mathrm{mg} \mathrm{kg}^{-1}\right)$, GL39 (5.13 mg kg-1), PK3 (6.31 $\left.\mathrm{mg} \mathrm{kg}^{-1}\right)$, PK15 (5.34 $\left.\mathrm{mg} \mathrm{kg}^{-1}\right)$, PK17 (7.49 $\left.\mathrm{mg} \mathrm{kg}^{-1}\right)$ and PK18 (7.06 mg kg-1) exhibited elevated levels of PAEs and at these ten locations large amounts of plastic film and compost fertilizers had been used for several years. Another high PAE location was site SS18 (7.14 $\mathrm{mg} \mathrm{kg}^{-1}$ ) which was covered with new plastic film.

DMP, DEP, DnBP, BBP, DEHP and DnOP, respectively, were detected in $57.4,76.2,87.7,61.5,100$, and $80.3 \%$ of the samples analyzed. The individual PAE concentrations were in the descending sequence DEHP $>$ DnOP $>$ DnBP $>$ DEP $>$ DMP $>$ BBP. DnBP and DEHP tended to be the dominant PAEs in the soils with average concentrations of $0.19 \pm 0.27$ and $1.72 \pm 1.79 \mathrm{mg} \mathrm{kg}^{-1}$, respectively.

\subsection{Variation in PAEs with different use modes of plastic film}

The individual concentrations of the 6 PAEs and $\Sigma_{\text {PAEs }}$ in vegetable production soils with different use modes of plastic film are listed in 


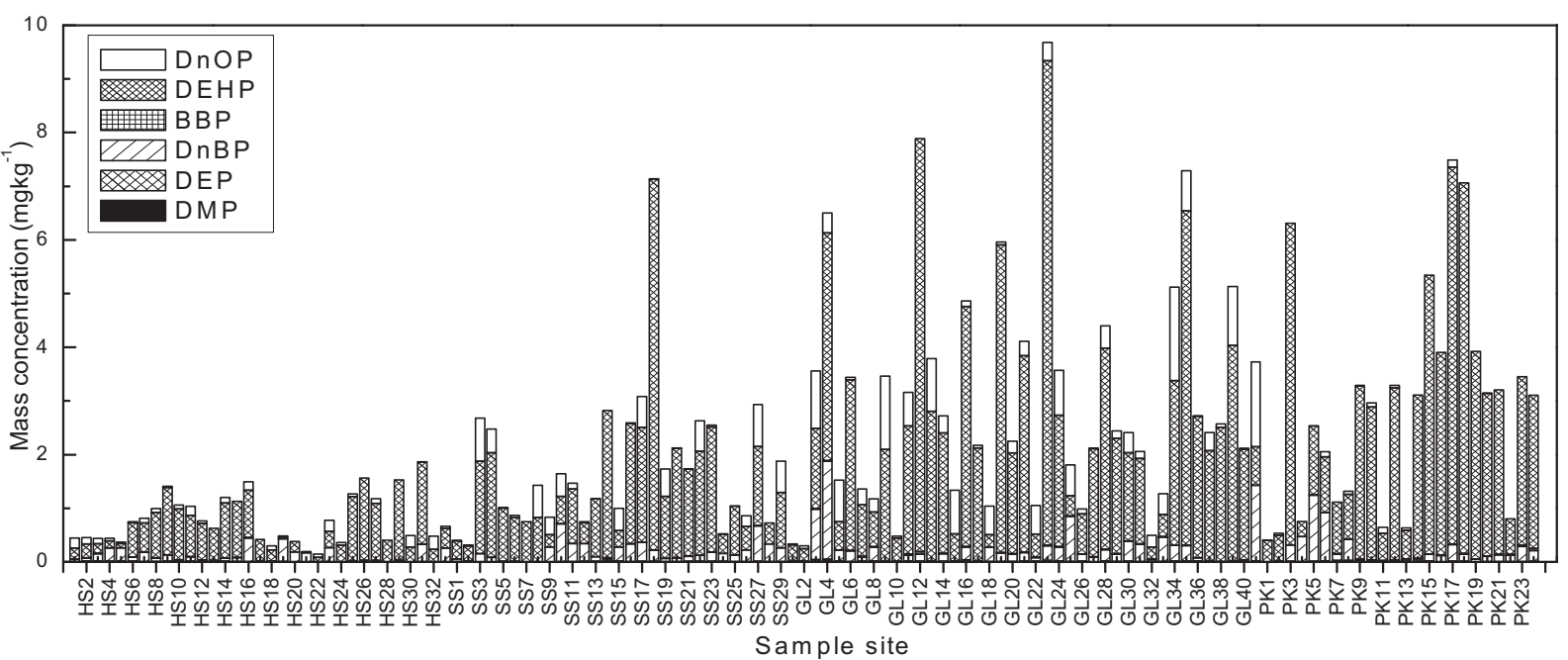

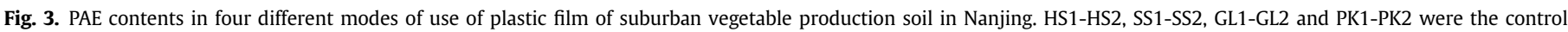
sampling sites.

Table 1. $\Sigma_{\text {PAEs }}$ concentrations with different modes use of plastic film exhibited the increasing order HS $\left(0.81 \pm 0.46 \mathrm{mg} \mathrm{kg}^{-1}\right)<\mathrm{SS}$ $\left(1.87 \pm 1.33 \mathrm{mg} \mathrm{kg}^{-1}\right)<\mathrm{PK}\left(3.16 \pm 1.99 \mathrm{mg} \mathrm{kg}^{-1}\right) \approx \mathrm{GL}$ $\left(3.18 \pm 2.11 \mathrm{mg} \mathrm{kg}^{-1}\right)$.

As Fig. 4 shows, $\Sigma_{\text {PAEs }}$ in HS, SS, GL and PK soils with plastic film were 79.3, 421, 610 and 568\% higher than the control soils without plastic film. In the HS mode of use, soil DMP, DEP and DnOP contents in the presence of plastic film were lower than without it.

The $\Sigma_{\text {PAEs }}$ concentrations in soils from SS, GL and PK modes were significantly higher than those from HS mode $(P<0.05)$ but there was no difference between the GL and PK modes (Table 1). DEHP was the most abundant contaminant followed by DnBP and DnOP in the vegetable production soils, with very low concentrations of DMP, DEP and BBP. The average DnBP concentration in soils of HS mode was $0.116 \pm 0.127 \mathrm{mg} \mathrm{kg}^{-1}$, about $43.9,48.5$ and $58 \%$ of GL, PK and SS modes and the mean concentration of DEHP was $0.617 \pm 0.471 \mathrm{mg} \mathrm{kg}^{-1}$, about 21.7, 25.3 and $43.6 \%$ of PK, GL and SS modes, respectively (Fig. 5).

\subsection{PAE concentrations in potential source materials}

PAE concentrations in some potential source materials were analyzed and the results are shown in Fig. 6. PAE concentrations varied widely in the different sources, with mulch film exhibiting the highest values followed by chicken manure, mushroom compost and polytunnel film, and duck manure contained the lowest PAE concentrations. The mean $\sum_{\mathrm{PAEs}}$ values in different sources ranged from 1.43 to $119.4 \mathrm{mg} \mathrm{kg}^{-1}$. Individual PAE concentrations in the different sources are listed in Table 3. PAE concentrations in plastic film of different colors were significantly $(P<0.05)$ different, with $\sum$ PAEs of $119.4 \pm 26.81$ and $50.8 \pm 18.13 \mathrm{mg} \mathrm{kg}^{-1}$ in white and black mulching film. The $\sum$ PAEs concentrations in chicken manure, spent mushroom compost, agricultural greenhouse film, pig manure, cow manure, commercial organic fertilizer, and duck manure were $6.84 \pm 6.54,6.40 \pm 0.27,4.89 \pm 1.59,4.57 \pm 2.84,3.65 \pm 0.59$, $2.95 \pm 3.62$, and $2.24 \pm 0.90 \mathrm{mg} \mathrm{kg}^{-1}$, respectively.

\section{Discussion}

\subsection{PAE concentrations in suburban vegetable soils}

PAEs were detected in all samples, indicating their ubiquity as environmental contaminants. Larger amounts of PAEs may have been released from plastic films and some widely-used fertilizers leading to elevated PAEs in the soils (Cai et al., 2008). Elevated PAE levels have previously been reported in soils with residual plastic film (Kong et al., 2012). Furthermore, the $\Sigma_{\text {PAEs }}$ content of some wide-used fertilizers in China was found to range from 0.001 to $2.80 \mathrm{mg} \mathrm{kg}^{-1}$ and sewage sludge composts with rice straw were in the range $9.8-18.0 \mathrm{mg} \mathrm{kg}^{-1}$ (Cai et al., 2007; Mo et al., 2008). The concentrations of PAEs in finished plastic products are in the range 10-60\% by weight (Hens and Caballos, 2003). The high levels of PAEs in soils may be attributed to the utilization of agricultural plastic film and fertilizers or proximity of the soils to plastics factories (Guan et al., 2007). Vegetables can take up substantial amounts of PAEs from new plastic film greenhouses (Fu and $\mathrm{Du}$, 2011). The variation in PAE concentrations among the different sampling sites may be related to the use modes of plastic film, the amounts of plastic film residues remaining or the age of the plastic greenhouse (Meng et al., 1996; Guo and Wu, 2011; Fu and Du, 2011).

The pattern of distribution of each PAE was in agreement with those in suburban vegetable soils (Kong et al., 2012) and in water (Xie et al., 2007), sediments (Srivastava et al., 2010), atmospheric particles (Ma et al., 2003) and biota (Adibi et al., 2003; Main et al., 2006). DnOP also exhibited elevated levels in our soils with a mean concentration of $0.22 \pm 0.33 \mathrm{mg} \mathrm{kg}^{-1}$, and this may have been derived from fertilizers, sediments and plastic film (Cai et al., 2007; Mo et al., 2008) and also from emission sources from the polymer industry and the production of vinyl flooring, synthetic leather, inks, adhesives and food products (Hens and Caballos, 2003; Kong et al., 2012). Longer/branching alkyl chain PAEs such as DnBP, BBP, DnOP and DEHP have been widely used as plasticizers in the polymer industry to increase the flexibility, workability and general handling properties of plastics and about $80 \%$ of all phthalates are used for this purpose (Hens and Caballos, 2003; Zeng et al., 2008, 2009). By 2002, the global production of DEHP and DBP had reached 394 and 134 thousand tons, respectively (Xu et al., 2008). Thus, the high concentrations of DnBP, DEHP and DnOP in our suburban vegetable soils were not unexpected.

\subsection{Variation in PAEs with different use modes of plastic film}

Different cultivation and management methods in the vegetable production systems may have introduced PAE contaminants into 


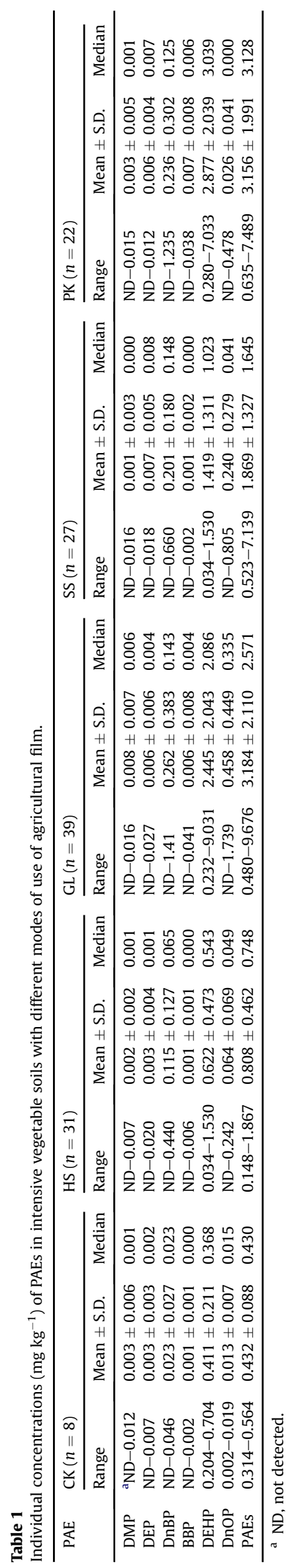

the soils (Xu et al., 2008). As a result, the mean DnBP and DEHP levels of SS, PK and GL were 8.7-11.4 and 3.5-7.0 times of those of control soil and 1.8-2.3 and 2.3-4.6 times those of HS mode. DnOP concentrations of the SS and GL modes were 3.8 and 7.2 times those of the HS mode and 9.2 and 17.6 times those of the PK mode. DMP, DEP and BBP concentrations in the vegetable soils showed no significant differences among the different use modes of plastic film. DnBP and DEHP were the main contaminants in the vegetable soils and DnOP was also a dominant pollutant in the GL and SS modes. High PAE concentrations in vegetable soils have also been found in some previous studies (Cai et al., 2005; Guan et al., 2007; Li et al., 2010; Zhang et al., 2009; Chen et al., 2011; Kong et al., 2012). The levels and variation in soil PAE concentrations are also affected by factors such as land use and soil properties (Xu et al., 2008; Zeng et al., 2009).

In the HS mode of use, soil DMP, DEP and DnOP contents in the presence of plastic film were lower than in without it. Compared to the other modes of film use studied, HS mode involved rotation of vegetables with flooded rice and this would have reduced the exposure of the soils to plastic film. This may explain the lower $\Sigma_{\text {PAEs }}$ concentrations in soil compared with the other three modes of film use. In GL and PK modes the individual PAE levels were higher than in control soil with the sole exception of DMP. DnBP and DEHP concentrations in soils from HS, SS, GL and PK modes were about $74.4-665$ and $115-808 \%$ higher than the controls. The $\Sigma_{\text {PAEs }}$ concentrations in soils from SS, GL and PK modes were significantly higher than those from HS mode $(P<0.05)$ but there was no difference between the GL and PK modes (Table 1). DEHP was the most abundant contaminant followed by DnBP and DnOP in the vegetable production soils, with very low concentrations of DMP, DEP and BBP. HS was the plastic film mode of use in which vegetable was rotated with flooded rice rotation and polytunnel plastic film was used for only about six months each year. In contrast, the other three modes of use involved the simultaneously use of greenhouse and mulching films over extended periods. In addition, vegetable cultivation had been practiced for only about 4 years in HS but at least 8 years in SS, GL and PK modes. Thus, HS mode showed the lowest PAE levels and GL exhibited the highest residual PAEs. High PAE levels in intensively managed vegetable production soils must therefore be considered in the design of intensive crop production systems.

\subsection{Comparison with soil PAE concentrations in other studies}

The PAE concentrations in the present study are compared with other published studies in Table 2. DMP, DEP, and BBP concentrations in agricultural or vegetable soils have been relatively low in all studies because they are readily degraded (Chou and Robert, 2006). Levels of PAEs in agricultural soils on the Leizhou Peninsula and at Hangzhou were similar to each other (Guan et al., 2007; Chen et al., 2011). The lowest PAE concentrations reported in China have been found at Nanchang (Xiong et al., 2008) and the highest at Guangdong (Cai et al., 2005; Zeng et al., 2008; Zhang et al., 2009; Li et al., 2010). The different stages of economic development of these two regions might be the main explanation for the difference in their soil PAE concentrations (Kong et al., 2012). The $\sum$ PAEs values in the present study were similar to those in agricultural soils at Tianjin. DnOP concentrations in our study were higher than in previous studies (Ma et al., 2003; Gibson et al., 2005; Guan et al., 2007), while DEP and BBP level were clearly lower than those reported at Guangzhou (Zeng et al., 2008; Li et al., 2010), the Pearl River Delta (Cai et al., 2005) and Hangzhou (Chen et al., 2011). The soil PAE concentrations in the present study differed significantly from those in other studies $(P<0.05)$. A sequence of decline in soil PAE concentrations in different cropping systems was found to follow 

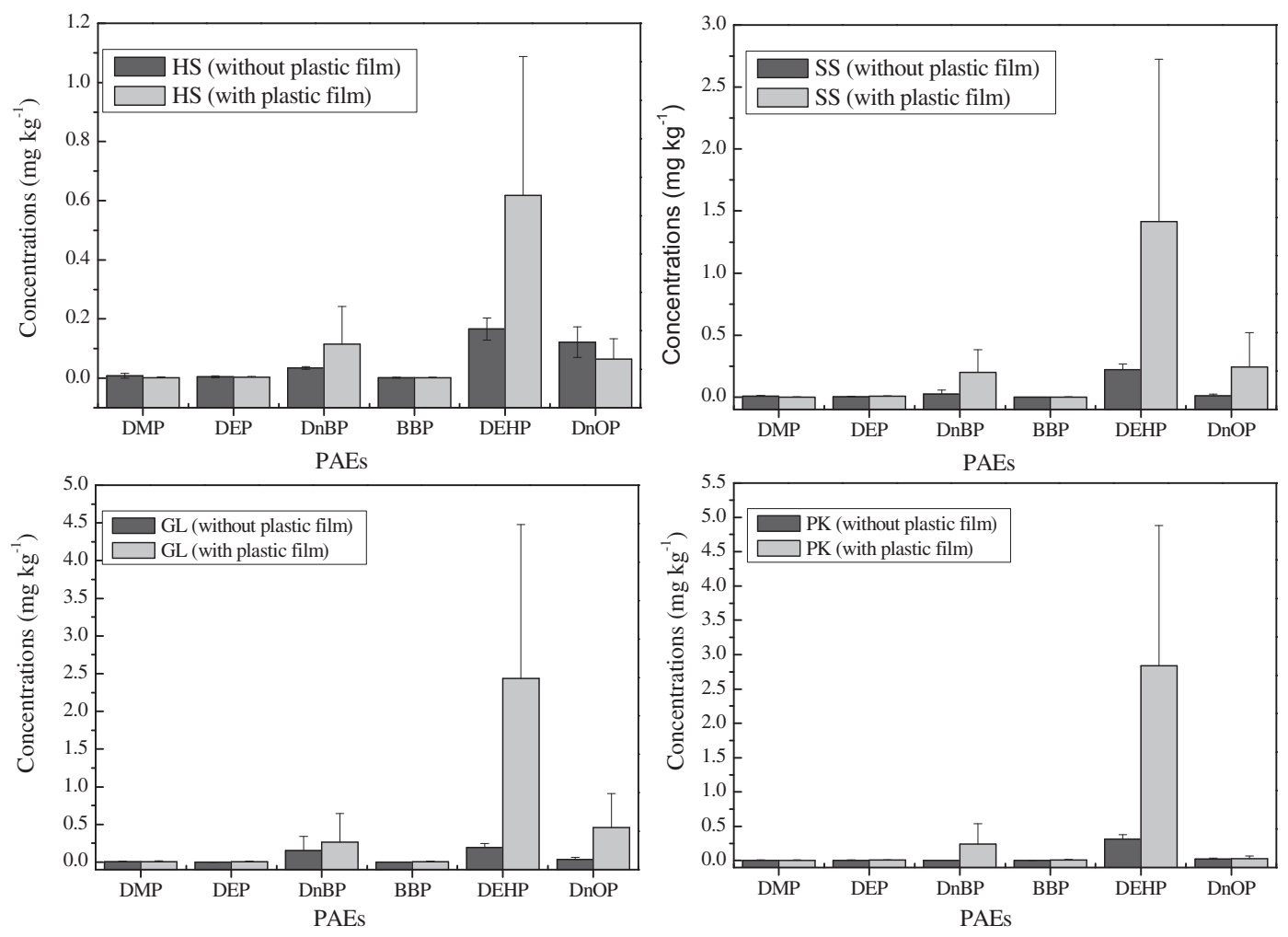

Fig. 4. The influence of plastic film on PAE concentrations in vegetable production soils in suburban Nanjing.

the trend sugarcane $\left(1.11 \mathrm{mg} \mathrm{kg}^{-1}\right)$, rice paddy $\left(0.86 \mathrm{mg} \mathrm{kg}^{-1}\right)$, vegetables $\left(0.61 \mathrm{mg} \mathrm{kg}^{-1}\right.$ ) and orchards $\left(0.60 \mathrm{mg} \mathrm{kg}^{-1}\right)$ (Guan et al., 2007). Extremely high concentrations of PAEs were found in cotton fields in Xinjiang province where plastic film had been used for many years, with ranges of ND-149 $\mathrm{mg} \mathrm{kg}^{-1}$ and ND-57.7 $\mathrm{mg} \mathrm{kg}^{-1}$ for DEHP and DnBP, respectively (Guo and $\mathrm{Wu}, 2011$ ). The PAE concentrations found in Chinese soils in the present study and in other Chinese studies are significantly higher than in agricultural soils in the Netherlands (Peijnenburg and Struijs, 2006), Denmark (Vikelsøe et al., 2002) and the United Kingdom (Gibson et al., 2005).

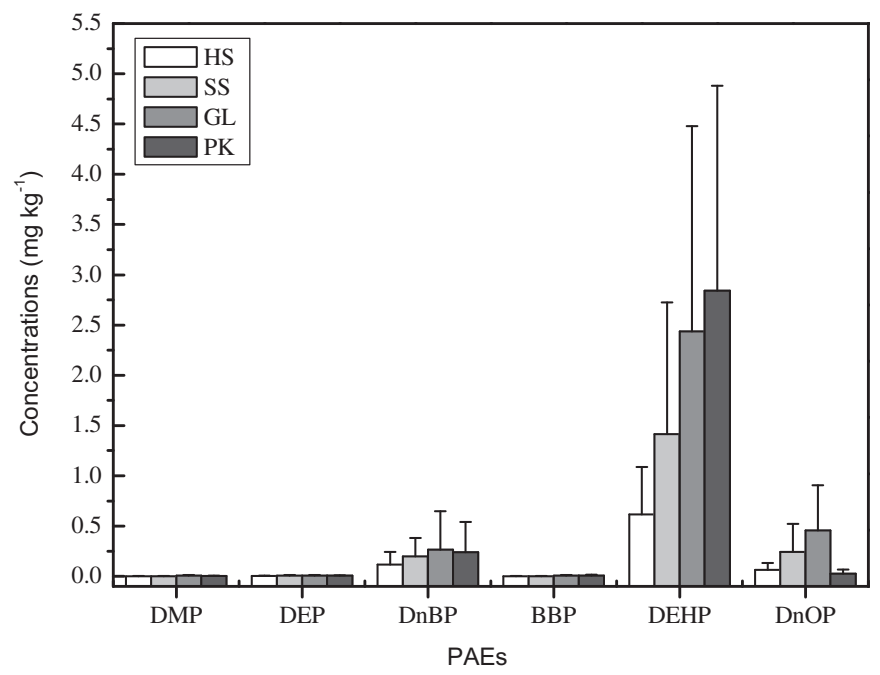

Fig. 5. The influence of the different modes of use of plastic film on vegetable production soils in suburban Nanjing.
PAE contamination of vegetable soils in China therefore seems to be particularly high.

\subsection{PAE concentrations in potential source materials}

The dominant PAE components in plastic film, poultry manure and commercial fertilizer were DnBP and DEHP, accounting for about $68.1-99.4 \%$ of the $\sum$ PAEs. This result is in accord with the PAE components in vegetable soils, and the different sources of PAEs may reflect the difference in soil PAE profiles (Cai et al., 2008). The main sources of PAEs in Nanjing vegetable soils are plastic films and various poultry manures, and especially mulching films. The higher the application rate of plastic film and poultry manure, the higher the PAE concentrations in the soils. In addition, the PAE components in plastic films are released to soils with the passage of time (Van Wezel et al., 2000; Hens and Caballos, 2003), and the longer the soils are covered with plastic film, the higher the soil PAE concentrations. PAEs in pesticides, irrigation water and aerial deposition were not analyzed in the present study. These are also potential sources (Xu et al., 2008; Zeng et al., 2008; Kong et al., 2012) and require investigation in future studies.

\subsection{Potential environment risk from PAEs in the vegetable soils of Nanjing}

Van Wezel et al. (2000) used (eco)toxicology and environmental chemistry data to derive environmental risk limits for DnBP and DEHP in fresh soils and sediments with $10 \%$ organic matter of 0.7 and $1.0 \mathrm{mg} \mathrm{kg}^{-1}$, respectively. The mean concentrations of DEHP in vegetable soils of GL, SS and PK were higher than $1.0 \mathrm{mg} \mathrm{kg}^{-1}$ while DnBP was lower than $0.7 \mathrm{mg} \mathrm{kg}$. Compared with the soil allowable concentrations and cleanup 


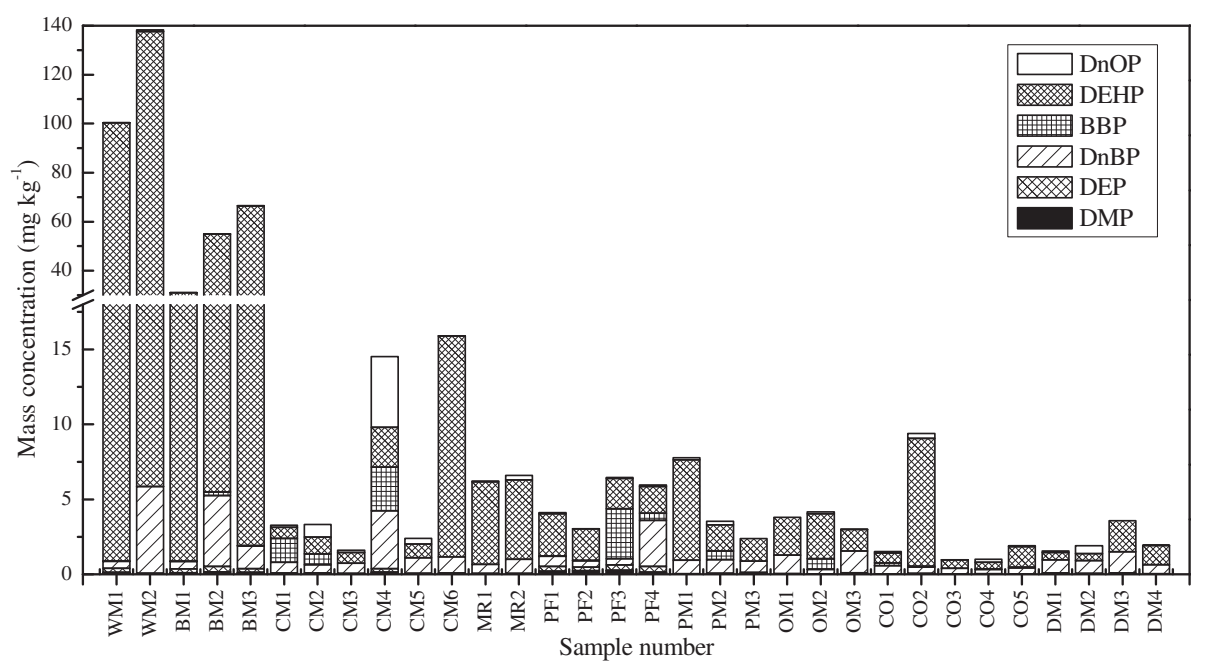

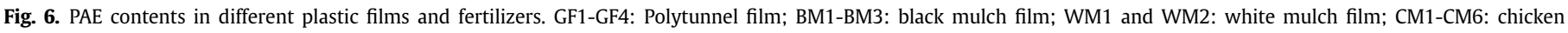

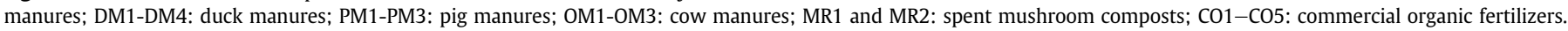

objectives of the 6 PAE compounds in the United States (Table 4), the levels of DMP, DEP and BBP in the present study were below the maximum allowable concentrations set in the United States by New York State Department of Environmental Conservation (2010), and there were no PAEs in vegetable soils from the different modes of use of plastic film that were higher than the recommended cleanup soil concentration. However, the DnBP concentrations in about 45, 74, 68 and $69 \%$ of HS, SS, PK and GL soil samples, the DEHP concentrations in about 14.7, 3.4 and $18.2 \%$ of GL, SS and PK soil samples and the DnOP concentrations in about $8 \%$ of GL soil samples exceeded the recommended allowable concentrations set by New York State Department of Environmental Conservation (2010). The potential risk of PAEs from different use modes of plastic film was in the ascending sequence $\mathrm{HS}<\mathrm{SS}<\mathrm{GL}<\mathrm{PK}$. The results show that application of large amounts of plastic film over long periods of time can raise PAEs concentrations and environmental risk in intensive vegetable production soils and the use of vegetable and flooded rice rotations as in HS mode may help to control the PAE risk in soils as suggested above. Guo and $\mathrm{Wu}$ (2011) also found that DBP and DEHP contents in cotton soils were high (28.3 and $128.7 \mathrm{mg} \mathrm{kg}^{-1}$ ) with long periods of plastic film utilization in Xinjiang, about two or three times higher than the recommended cleanup soil concentration (Zeng et al., 2008). High DnBP, DEHP and DnOP concentrations in soils might result in relatively high concentrations in vegetables (the subject of another paper) and represent a risk

Table 2

Concentrations of the six target PAEs in vegetable soils: comparison with other studies $\left(\mathrm{mg} \mathrm{kg}^{-1}\right)$.

\begin{tabular}{|c|c|c|c|c|c|c|c|c|}
\hline Soil utilization and location & DMP & DEP & DnBP & $\mathrm{BBP}$ & DEHP & DnOP & $\sum$ PAEs & Reference \\
\hline $\begin{array}{l}\text { Intensive vegetable soil, } \\
\text { Nanjing, China }\end{array}$ & ${ }^{\mathrm{b}} \mathrm{ND}-0.016$ & ND-0.018 & ND-1.41 & ND-0.041 & $0.034-9.03$ & ND-7.04 & $0.15-9.68$ & Present study \\
\hline Greenhouse soil, Jinan, China & ${ }^{\mathrm{a}} \mathrm{NA}$ & $0.12-2.21$ & $0.67-3.62$ & NA & $0.58-3.45$ & NA & & Meng et al., 1996 \\
\hline Uncultured soil, Denmark & NA & NA & $0.0021-0.45$ & $0-0.032$ & $0.012-1.90$ & $0.0012-0.067$ & & Vikelsøe et al., 2002 \\
\hline $\begin{array}{l}\text { Greenhouse soil, Beijing, } \\
\text { China }\end{array}$ & $<0.01-0.02$ & $<0.01-0.05$ & $0.34-1.66$ & & $0.22-0.74$ & $<0.09$ & & Ma et al., 2003 \\
\hline $\begin{array}{l}\text { Agricultural soil, United } \\
\text { Kingdom }\end{array}$ & 0.0001 & $0.0002-0.0009$ & $0.079-0.008$ & $0.0002-0.0008$ & $0.0222-0.0758$ & $0.0115-0.0137$ & & Gibson et al., 2005 \\
\hline $\begin{array}{l}\text { Vegetable soil, Pearl River } \\
\text { Delta, China }\end{array}$ & ND-0.068 & ND-1.77 & ND-20.55 & ND-1.48 & $2.82-25.11$ & ND-0.92 & $3.0-45.7$ & Cai et al., 2005 \\
\hline Vegetable soil, Netherlands & NA & NA & 0.06 & NA & 0.0318 & NA & & $\begin{array}{l}\text { Peijnenburg and } \\
\text { Struijs, } 2006\end{array}$ \\
\hline $\begin{array}{l}\text { Agricultural soil, Leizhou } \\
\text { Peninsula, China }\end{array}$ & ND-0.071 & ND-0.076 & ND-1.77 & ND-0.054 & ND-1.39 & ND -0.073 & ND-5.45 & Guan et al., 2007 \\
\hline $\begin{array}{l}\text { Agricultural soil, Guangzhou, } \\
\text { China }\end{array}$ & $0.001-0.157$ & $0.001-0.178$ & $0.009-2.74$ & ND-1.58 & $0.107-29.4$ & ND-0.084 & $0.22-33.6$ & Zeng et al., 2008 \\
\hline $\begin{array}{l}\text { Agricultural soil, Nanchang, } \\
\text { China }\end{array}$ & NA & ND & ND-0.112 & NA & ND-0.274 & ND-0.044 & ND-0.39 & Xiong et al., 2008 \\
\hline $\begin{array}{l}\text { Vegetable soil, Dongguan, } \\
\text { China }\end{array}$ & ND & ND -0.830 & ND -0.282 & ND-0.190 & $0.007-1.47$ & ND-0.013 & $0.39-26.0$ & Zhang et al., 2009 \\
\hline $\begin{array}{l}\text { Vegetable soil, Guangzhou, } \\
\text { China }\end{array}$ & ND & ND-1.2 & $1.1-4.3$ & ND & $8.0-57.4$ & ND & $9.7-58.9$ & Li et al., 2010 \\
\hline $\begin{array}{l}\text { Greenhouse soil, Hangzhou, } \\
\text { China }\end{array}$ & ND & $0.06-1.49$ & $0.14-0.35$ & $0.03-0.16$ & $0.81-2.20$ & $0.10-0.25$ & $1.9-4.36$ & Chen et al., 2011 \\
\hline $\begin{array}{l}\text { Cotton filed soil, Xingjiang, } \\
\text { China }\end{array}$ & ND-3.01 & ND-2.42 & $11.2-57.7$ & NA & $104-149$ & NA & $124-1232$ & Guo and Wu, 2011 \\
\hline Vegetable soil, Tianjin, China & $0.002-0.101$ & $0.002-0.114$ & $0.013-0.285$ & $0.000-0.358$ & $0.028-4.17$ & $0.000-9.78$ & $0.05-10.04$ & Kong et al., 2012 \\
\hline
\end{tabular}

\footnotetext{
a NA, not analyzed.

b ND, not detected.
} 
Table 3

Individual concentrations ( $\mathrm{mg} \mathrm{kg}^{-1}$ ) of PAEs in different source materials.

\begin{tabular}{lllllllr}
\hline Source material & DMP & DEP & DnBP & BBP & DEHP & DnOP & $\sum$ PAEs \\
\hline White mulch film & 0.08 & 0.14 & 3.13 & 0.00 & 115.59 & 0.44 & 119.39 \\
Black mulch film & 0.12 & 0.30 & 2.25 & 0.09 & 48.04 & 0.04 & 50.84 \\
Chicken manure & 0.05 & 0.08 & 1.32 & 0.87 & 3.49 & 1.04 & 6.84 \\
$\quad \begin{array}{l}\text { Spent mushroom } \\
\quad \text { compost }\end{array}$ & 0.02 & 0.04 & 0.76 & 0.00 & 5.42 & 0.16 & 6.40 \\
$\begin{array}{l}\text { Polytunnel film } \\
\text { Pig manure }\end{array}$ & 0.21 & 0.33 & 1.15 & 0.96 & 2.19 & 0.06 & 4.89 \\
$\quad$ Cow manure & 0.03 & 0.05 & 0.86 & 0.20 & 3.30 & 0.13 & 4.57 \\
$\quad$ Commercial organic & 0.03 & 0.02 & 1.00 & 0.24 & 2.32 & 0.05 & 3.65 \\
$\quad 0.02$ & 0.02 & 0.40 & 0.06 & 2.31 & 0.14 & 2.95 \\
$\quad$ fertilizer & & & & & & & \\
$\quad$ Duck manure & 0.03 & 0.03 & 0.94 & 0.00 & 1.08 & 0.16 & 2.24 \\
\hline
\end{tabular}

\section{Table 4}

Soil allowable concentrations and cleanup objectives of the six targets PAE compounds in the United States.

\begin{tabular}{llc}
\hline Compound & $\begin{array}{l}\text { Allowable concentration } \\
\mathrm{mg} \mathrm{kg}^{-1}\end{array}$ & $\begin{array}{l}\text { Cleanup objective value } \\
\mathrm{mg} \mathrm{kg}^{-1}\end{array}$ \\
\hline DMP & 0.02 & 2.00 \\
DEP & 0.07 & 7.10 \\
DnBP & 0.08 & 8.10 \\
BBP & 1.22 & 50.00 \\
DEHP & 4.35 & 50.00 \\
DnOP & 1.20 & 50.00 \\
\hline
\end{tabular}

to human health (Yin et al., 2003; Fu and Du, 2011). Efforts must therefore be made to control the use of plastic film in vegetable production systems.

\section{Conclusions}

Overall, DMP, DEP, DnBP, BBP, DEHP and DnOP were found in about $57.4,76.2,87.7,61.5,100$, and $80.3 \%$ of vegetable soils in suburban Nanjing. The soil $\sum$ PAEs concentrations ranged from 0.15 to $9.68 \mathrm{mg} \mathrm{kg}^{-1}$, with a median value of $1.70 \mathrm{mg} \mathrm{kg}^{-1}$. DnBP, DEHP and DnOP were the major PAEs present, with concentrations of $0.19 \pm 0.27,1.72 \pm 1.79$ and $0.22 \pm 0.33 \mathrm{mg} \mathrm{kg}^{-1}$, respectively. PAE concentrations in soils increased in the use mode of plastic film sequence $\mathrm{HS}\left(0.81 \pm 0.46 \mathrm{mg} \mathrm{kg}^{-1}\right)$, SS $\left(1.88 \pm 1.33 \mathrm{mg} \mathrm{kg}^{-1}\right)$, PK $\left(3.16 \pm 1.99 \mathrm{mg} \mathrm{kg}^{-1}\right)$ and GL $\left(3.18 \pm 2.11 \mathrm{mg} \mathrm{kg}^{-1}\right)$. The $\sum$ PAEs concentrations were lower than reported in other regions of China but higher than in other parts of the world. Source analysis indicated that plastic films and poultry manure were the dominant sources of PAEs in the vegetable production soils of Nanjing. Mulching film exhibited the highest PAEs levels, and the dominant PAE components in plastic film and fertilizers were matched the soil PAE components. The use mode of plastic film, and the time over which the soil is exposed can influence PAE concentrations in vegetable soils. A rotation of vegetable and flooded rice significantly decreased the soil PAE concentrations. The potential risk from PAEs in GL and PK modes was greater than that in HS and SS modes. However, further studies are required on the effects of different modes of use of plastic film on plant PAE uptake and the associated human health risk.

\section{Acknowledgments}

This study was supported by the Chinese National Environmental Protection Special Fund for Scientific Research on Public Causes (201109018 and 2010467016) and the Postdoctoral Research Funding Plan of Jiangsu Province (1202050C).

\section{References}

Adibi, J.J., Perera, F.P., Jedrychowski, W., Camann, D.E., Barr, D., Jacek, R. Whyatt, R.M., 2003. Prenatal exposures to phthalates among women in New York City and Krakow, Poland. Environmental Health Perspectives 111, 17191722

Cai, Q.Y., Mo, C.H., Li, Y.H., Zeng, Q.Y., Wang, B.G., Xiao, K.E., Li, H.Q., Xu, G.S., 2005. Preliminary study of PAEs in soils from typical vegetable fields in areas of Guangzhou and Shenzhen, South China. Acta Ecologica Sinica 25, 283-288 (in Chinese).

Cai, Q.Y., Mo, C.H., Wu, Q.T., Zeng, Q.Y., Katsoyiannis, A., 2007. Quantitative determination of organic priority pollutants in the composts of sewage sludge with rice straw by gas chromatography coupled with mass spectrometry. Journal of Chromatography A 1143, 207-214.

Cai, Q.Y., Mo, C.H., Wu, Q.T., Katsoyiannis, A., Zeng, Q.Y., 2008. The status of soil contamination by semivolatile organic chemicals (SVOCs) in China: a review. Science of the Total Environment 389, 209-224.

Chen, Y.S., Luo, Y.M., Zhang, H.B., Song, J., 2011. Preliminary study on PAEs pollution of greenhouse soil. Acta Pedologica Sinica 48, 516-522 (in Chinese).

Chou, K., Robert, O.W., 2006. Phthalates in food and medical devices. Journal of Medical Toxicology 2, 126-135.

China Ministry of Agriculture, 2011. China Agriculture Yearbook. China Agriculture Press, Beijing.

CPPIU (China Plastics Process Industry Union), 2011. China Plastics Industry Yearbook 2011. Chemical Industry Press, Beijing.

Fu, X.W., Du, Q.Z., 2011. Uptake of di-(2-ethylhexyl) phthalate of vegetables from plastic film greenhouses. Journal of Agricultural and Food Chemistry 59, 1158511588.

Gao, H.J., Jiang, X., Wang, F., Wang, D.Z., Bian, Y.R., 2005. Residual levels and bioaccumulation of chlorinated persistent organic pollutants (POPs) in vegetables from suburbs of Nanjing, People's Republic of China. Bulletin of Environmental Contamination and Toxicology 74, 673-680.

Gibson, R., Wang, M.J., Padgett, E., Beck, A.J., 2005. Analysis of 4-nonylphenols, phthalates, and polychlorinated biphenyls in soils and biosolids. Chemosphere $61,1336-1344$

Gu, C.L., Hu, L.Q., Zhang, X.M., Wang, X.D., Guo, J., 2011. Climate change and urbanization in the Yangtze River Delta. Habitat International 35, 544-552.

Guan, H., Wang, J.S., Wan, H.F., Li, P.X., Yang, G.Y., 2007. PAEs pollution in soils from typical agriculture area of Leizhou Peninsula. Journal of Agro-Environment Science 26, 622-628 (in Chinese).

Guo, D.M., Wu, Y., 2011. Determination of phthalic acid esters of soil in south of Xinjiang cotton fields. Arid Environmental Monitoring 25, 76-79 (in Chinese).

Hens, G.A., Caballos, A.M.P., 2003. Social and economic interest in the control of phthalic acid esters. Trends in Analytical Chemistry 22, 847-857.

Hu, X., Ding, Z.H., 2009. Lead/cadmium contamination and lead isotopic ratios in vegetables grown in peri-urban and mining/smelting contaminated sites in Nanjing, China. Bulletin of Environmental Contamination and Toxicology 82 $80-84$.

Khai, N.M., Ha, P.Q. Öborn, I., 2007. Nutrient flows in small-scale peri-urban vegetable farming systems in Southeast Asia: a case study in Hanoi. Agriculture, Ecosystems \& Environment 122, 192-202.

Kong, S.F., Ji, Y.Q., Liu, L.L., Chen, L., Zhao, X.Y., Wang, J.J., Bai, Z.P., Sun, Z.R., 2012 Diversities of phthalate esters in suburban agricultural soils and wasteland soil appeared with urbanization in China. Environmental Pollution 170, 161-168.

Li, M., Cai, Q.Y., Zeng, Q.Y., Lu, X.H., 2010. Occurrence of phthalic acid esters in soils and vegetables from green food and organic vegetable fields. Journal of Anhui Agricultural Sciences 38, 10189-10191 (in Chinese)

Ma, L.L., Chu, S.G., Xu, X.B., 2003. Phthalate residues in greenhouse soil from Beijing suburbs, People's Republic of China. Bulletin of Environmental Contamination and Toxicology 71, 394-399.

Main, K.M., Mortensen, G.K., Kaleva, M.M., Boisen, K.A., Damgaard, I.N., Chellakooty, M., Schmidt, I.M., Suomi, A.M., Virtanen, H.E., Petersen, D.V., Andersson, A.M., Toppari, J., Skakkebaek, N.E., 2006. Human breast milk contamination with phthalates and alterations of endogenous reproductive hormones in infants three months of age. Environmental Health Perspectives $114,270-276$.

McKee, R., Butala, J., David, R., Gan, G., 2004. NTP center for the evaluation of risks to human reproduction reports on phthalates, addressing the data gaps. Reproductive Toxicology 18, 1-22.

Meng, P.R., Wang, X.K., Xu, G.T., Wang, X.M., Li, H., 1996. Determination and distribution of phthalate alkyl esters in soil in Jinan. Environmental Chemistry 15 427-432 (in Chinese).

Mo, C.H., Cai, Q.Y., Li, Y.H., Zeng, Q.Y., 2008. Occurrence of priority organic pollutants in the fertilizers, China. Journal of Hazardous Materials 152, 1208-1213.

New York State Department of Environmental Conservation, 2010. CP-51/Soil Cleanup Guidance. http://www.dec.ny.gov/docs/remediation_hudson_pdf/ cpsoil.pdf.

Pedersen, G.A., Jensen, L.K., Fankhauser, A., Biedermann, S., Petersen, J.H., Fabech, B., 2008. Migration of epoxidized soybean oil (ESBO) and phthalates from twist closures into food and enforcement of the overall migration limit. Food Additives \& Contaminants $25,503-512$.

Peijnenburg, W.J.G.M., Struijs, J., 2006. Occurrence of phthalate esters in the environment of the Netherlands. Ecotoxicology and Environmental Safety 63, 204215. 
Srivastava, A., Sharma, V.P., Tripathi, R., Kumar, R., Patel, D.K., Mathur, P.K., 2010 Occurrence of phthalic acid esters in Gomti River sediment, India. Environmental Monitoring and Assessment 169, 397-406.

Tao, S., Xu, F.L., Wang, X.J., Liu, W.X., Gong, Z.M., Fang, J.Y., Zhu, L.Z., Luo, Y.M., 2005 Organochlorine pesticides in agricultural soil and vegetables from Tianjin, China. Environmental Science \& Technology 39 (8), 2494-2499.

United States Environmental Protection Agency (USEPA), 2013. Electronic Code of Federal Regulations, Title 40-Protection of Environment, Part 423-Steam Electric Power Generating Point Source Category. Appendix A to Part 423-126, Priority Pollutants. http://www.ecfr.gov/cgi-bin/text-idx?c=ecfr\& $\mathrm{SID}=\mathrm{b} 960051 \mathrm{a} 53 \mathrm{c} 9015 \mathrm{~d} 817718 \mathrm{~d} 71 \mathrm{f} 1617 \mathrm{~b} 7 \& \mathrm{rgn}=\mathrm{div} 5 \& \mathrm{view}=$ text $\&$ node $=40$, 30.0.1.1.23\&idno $=40 \# 40: 30.0 .1 .1 .23 .0 .5 .9 .9$.

Van Wezel, A.P., Van Vlaardingen, P., Posthumus, R., Grommentijn, G.H., Sijm, D.T.H. 2000. Environmental risk limits for two phthalates, with special emphasis on endocrine disruptive properties. Ecotoxicology and Environmental Safety 46, 305-321.

Vikelsøe, J., Thomsen, M., Carlsen, L., 2002. Phthalates and nonylphenols in profiles of differently dressed soils. Science of the Total Environment 296, 105-116.

Wang, W.X., Zhang, Y.L., Wang, S.L., Fan, C.Q., Xu, H., 2012. Distributions of phthalic esters carried by total suspended particulates in Nanjing, China. Environmental Monitoring and Assessment 184 (11), 6789-6798.

Xia, X.H., Yang, L.Y., Bu, Q.W., Liu, R.M., 2011. Levels, distribution, and health risk of phthalate esters in urban soils of Beijing, China. Journal of Environmenta Quality 40, 1643-1651.
Xie, Z., Ebinghaus, R., Temme, C., Lohmann, R., Caba, A., Ruck, W., 2007. Occurrence and air-sea exchange of phthalates in the Arctic. Environmental Science \& Technology 41, 4555-4560.

Xiong, P.X., Gong, X., Deng, L., 2008. Analysis of PAE pollutants in farm soil and water samples in Nanchang city. Chemistry Online 8, 636-640 (in Chinese).

Xu, G., Li, F.S., Wang, Q.H., 2008. Occurrence and degradation characteristics of dibutyl phthalate (DBP) and di-(2-ethylhexyl) phthalate (DEHP) in typical agricultural soils of China. Science of the Total Environment 393, 333-340.

Yin, C.Q., Jiang, X., Yang, X.L., Bian, Y.R., Wang, F., 2008. Polycyclic aromatic hydrocarbons in soils in the vicinity of Nanjing, China. Chemosphere 73, 389-394.

Yin, R., Lin, X.G., Wang, S.G., Zhang, H.Y., 2003. Effect of DBP/DEHP in vegetable planted soil on the quality of capsicum fruit. Chemosphere 50, 801-805.

Zhang, M.S., Li, M.Y., Wang, J.Y., Wang, Q.J., Luo, H.H., He, Z.Z., He, J.W., Mo, C.H., 2009. Occurrence of phthalic acid esters (PAEs) in vegetable fields of Dongguan City. Guangdong Agricultural Sciences 6, 172-180 (in Chinese).

Zeng, F., Cui, K.Y., Xie, Z.Y., Wu, L.N., Liu, M., Sun, G.Q., Lin, Y.J., Luo, D.L., Zeng, Z.X., 2008. Phthalate esters (PAEs): emerging organic contaminants in agricultural soils in peri-urban areas around Guangzhou, China. Environmental Pollution $156,425-434$

Zeng, F., Cui, K.Y., Xie, Z.Y., Wu, L.N., Luo, D.L., Chen, L.X., Lin, Y.J., Liu, M., Sun, G.X., 2009. Distribution of phthalate esters in urban soils of subtropical city, Guangzhou, China. Journal of Hazardous Materials 164, 1171-1178. 